\title{
Editorial JeDEM Vol. 12, No. 2 (2020)
}

\section{Judith Schoßböck \& Noella Edelmann}

\author{
Department for E-Governance and Administration, Danube University Krems \\ \{noella.edelmann, judith.schossboeck\}@donau-uni.ac.at
}

Welcome to the new issue of JeDEM!

This second part of JeDEM Vol. 12 comprises the ongoing papers submitted to our platinum open access journal during the second half of 2020 that made it through our double-blind review process. (Have you ever wondered why we define ourselves as platinum? Then we recommend this article titled "Noble metals for a noble cause" by Jean-Sébastien Caux).

But before we dive into the content, let us tell you a bit about what else we have been up to. This year, the thematic trends in JeDEM and the motivation of its users to publish open access has been the topic of two research outputs of the editors. One is based on a survey we did within the JeDEM community, and one based on data-mining of journal content in order to derive topical trends and insights for journal editors. If you are interested in the outcome, please check out the links below!

Additionally, we are now a member of OASPA (the Open Access Scholarly Publishers Association), and have been working together with our chief editor Anneke Zuiderwijk to improve the vision of the journal. As always, open data and co-creation will stay a big thematic focus - by all means check out our current call for papers if you are working on related projects.

In line with our thematic focus of JeDEM throughout the years, this issue stays true to one of our most covered topics: e-participaton and digital transformation.

The article by S. De Paoli and P. Forbes offers a conceptual analysis and a case study research on the design of e-Participation in environmental policy-making for young people. Connecting environmental action to e-participation research is something worthwhile and highly relevant these times, we find, and indeed the paper confirms that environmental action can increase e-participation capacity in environmental policy-making for young people. After reading this article, you will know about the core dimensions of environmental action for young people defined, but also how it is possible to seamlessly connect political communication, social theory and technology in environmental e-participation. Furthermore, the paper offers some practical recommendations for the design and conduction of e-participation.

The article by C. Abusleme focuses on nothing more than Cracking the Political Code - precisely the one of E-participation in Colombia. This work focuses on the nation-wide project Urna de Cristal and analyses three criteria: Inclusion, participation and deliberation. Importantly, the evidence suggests 
that the enactment of the project reflected the government's intention of preventing the policy process from becoming more participatory and deliberative. However, some data also suggests that the government tried to render this process more inclusive. This shows once more that technology enactment in the public sector is always tied to political complexity, and that ICTs capability of provoking change is always tied to a variety of political, cultural, organizational and budgetary factors. We can also recommend this article if you want to find out why the study of e-participation remains politically biased, or for a critical review of the existing e-participation literature (and the technodeterministic perspective that is often emphasised in this context).

With the next article by M. Chatwin we learn about the nascent movement that is the Civic Tech Ecosystem, and how it can be improved with view to Monitoring and Evaluation. Highlighting several challenges, the paper suggests that a theory-based evaluation approach is able to contribute to the growth and sustainability of the movement. This paper applies the early steps of contribution analysis to two distinct Canadian civic tech projects to demonstrate its feasibility for civic tech. The first is a fellowship program from Code for Canada aimed at accelerating digital transformation within government, the second BetaCity YEG, a community civic tech group in Edmonton highlighting a grassroots approach.

Finally, the article by A. Windarti titled in the form of the question Is Accessibility of Internet Financial Reporting Evolving Towards More Compliance of Disclosure? deals with the crucial community demand of financial transparency. Transparency is an expansive idea which is identified with the accessibility of data (the supply side of transparency). The author analyses the effect of financial performance on compliance in the context of internet financial reporting (IFR) through e-government. Based on case studies from provincial governments throughout Indonesia, this study provides empirical data about the relevance of IFR accessibility.

All papers published with JeDEM are also listed with Scopus. Furthermore, they are aggregated with CORE, one of the world's largest collections of open access research papers, offering authors several options for disseminating their work.

Last but not least: If you want to become a reviewer for a journal, please do not hesitate to register by creating a user account on our website. Don't forget to specify your reviewing interests (the more we know about them, the better $(-)$ ), and that your efforts can be recorded with ReviewerCredits.com if you register. If you do not know this tool yet - we very much recommend checking out their website, instructions, free training and how-to!

We strive to improve our already rapid publishing process in the future, but if you have any feedback or suggestions, we are always happy to hear from you!

Enjoy reading the last issue of the year, and see you on the other side, in 2021! Until then, stay safe. 
Links:

- Check out our presentation related to JeDEM at the Munin Conference - a joint project of Gdansk University of Technology, Danube University Krems and Delft University of Technology. The Munin Conference is an annual conference on scholarly publishing and communication, primarily revolving around open access, open data and open science.

- We have published a paper on JeDEM as a case study in the journal Publications. If you want to know more about the motivations to publish open access of our community, this is for you: Open Access Perceptions, Strategies, and Digital Literacies: A Case Study of a Scholarly-led Jornal

- Check out our Special Issue CFP on Co-creation and Participation Fueled by Open Data: Evidence and Impact

- $\quad$ ReviewerCredits.com: Instructions, free training and how-to for reviewers

- Worth a read: "Noble metals for a noble cause" by Jean-Sébastien Caux, founder of SciPost.org

\begin{abstract}
About the Editors
Noella Edelmann completed her Psychology Degree at the University of Strathclyde, UK and Masters' Degrees at the University of London, UK and the Danube University Krems, Austria. She received her PhD from the Tallinn University of Technology, Estonia where she focused on the importance of online lurking in the context of e-participation. Currently she is a senior researcher at the Department for Governance and Administration at the Danube University Krems. Her main research interests are the digital transformation and the use of social media in the public sector, e-participation, Open Access and scholarly communication. She is involved in the EU-funded projects such as the H2020 Inclusive Governance Models and ICT Tools for Integrated Public Service Co-Creation and Provision, and national projects funded by the Lower Austrian Regional Government, the Austrian Ministry of Digital and Economic Affairs (BMDW) and the Ministry of Civil Service and Sport. Noella is the Managing Editor of the international Open Access eJournal for E- Democracy and Open Government (JeDEM), Chair of the Social Media Track at the EGOV-CeDEM-ePart Conference and a member of IFIP WG 8.5 and OASPA.

Judith Schoßbock is a research fellow at the Centre for E-Governance at Danube University Krems, Austria and a HKPFS award recipient at the Department for Media and Communication at City University Hong Kong. She is managing editor of the open access e-journal JeDEM (jedem.org). At Danube University, she was inter alia involved in research projects covering electronic participation, civic online engagement, e-literacy, egovernance and open access.
\end{abstract}

